\title{
A Novel Mechanical Dispersion and Molecular Ordering in Styrene-Butadiene-Styrene Triblock Copolymer Films
}

\author{
Akira TanaKa*, Yoshikazu Jono, Noboru WaKabayashi, \\ Koh-hei NiTTA, and Shigeharu ONOGI \\ Department of Polymer Chemistry, Faculty of Engineering, \\ Kyoto University, Kyoto 606, Japan
}

(Received October 29, 1990)

\begin{abstract}
The dynamic mechanical properties were measured for styrene-butadiene-styrene triblock copolymer (SBS) films cast from solution in tetrahydrofuran containing $10 \%$ methyl ethyl ketone by volume. On the $\tan \delta T$ plots, a novel dispersion was observed around $65^{\circ} \mathrm{C}$. The dispersion became bigger by physical aging, and it disappeared by heat-treating at $60^{\circ} \mathrm{C}$. The similar dispersion was also observed on the films cast from cyclohexane solution. To investigate the origin of the dispersion, the ultrasonic velocity and attenuation coefficient, density, and DSC were measured for as-cast, aged, and heat-treated films. It was suggested that the dispersion can be ascribed to the molecular ordering formed in polystyrene molecules under nonequilibrium circumstances.

KEY WORDS Local Ordering / Loss Tangent / Ultrasonic Velocity / Ultrasonic Attenuation / SBS Triblock Copolymer / MONE /
\end{abstract}

Does local order exist in nominally glassy polymers? This question seems to be a long standing issue. Some experimental works ${ }^{1-8}$ have suggested that there is local order in the usually called amorphous polymers. Some theories have predicted that repulsive and/or attractive forces can cause supermolecular ordering not only in polymer glasses but also in polymer melts. Onsager theory ${ }^{9}$ in which only repulsive force is taken into account has successfully predicted lyotropic nematic-isotropic transition for rigid-chain polymers. On the other hand, Meier-Saupe theory ${ }^{10}$ in which attractive force is taken into account has predicted thermotropic nematic-isotropic transition for semirigid polymers containing regions of rigid and flexible fragments. Thus, any kinds of forces must induce molecular ordering.

In the nonequilibrium state in which potential energy of polymer molecules differs from place to place, potential gradient exists within a molecule and/or between molecules. The potential gradient possibly causes molecular ordering even in flexible-chain polymers. We call this molecular ordering as MONE (molecular ordering which is formed under nonequilibrium state). The nonequilibrium state possibly appears in the process of phase transitions such as precipitation and crystallization, and in the process of phase separation in multi-component systems. Hence, it can be expected that MONE possibly appears in block copolymer systems.

The purpose of this study is to show that MONE appears in styrene-butadiene-styrene triblock copolymer (designated as SBS) films, and to examine the effects of thermal history and casting solvent on the formation and/or development of MONE.

For the sake of characteristics of SBS polymer as well as utilities as elastomers,

\footnotetext{
* To whom correspondence should be addressed.
} 


\section{A. TANAKA et al.}

extensive work has been carried out on this polymer in past two decades. The morphology of SBS films depends not only upon the composition of styrene and butadiene blocks but also upon the cating solvent. ${ }^{1-16}$ Using the SBS films having different kinds of morphology, authors have examined the effect of morphology on the nonlinear viscoelastic properties. ${ }^{16}$ As was expected, the viscoelastic properties largely varied with the morphology. However, the nonlinearity did not directly depend upon the morphology, represented by domain shapes such as particles, rods, and lamellae. For example, the nonlinearity changed significantly with physical aging, even though the domain shape did not change with physical aging. It was supposed that a smaller scale of structural change than domain size affects to the nonlinearity. The structural change seems to be the formation of MONE. This supposition is one of the motives for this study.

\section{EXPERIMENTAL}

SBS used in this study was a commercial polymer, Kraton 1101 (Shell Chem. Co.). This sample contains 28 weight percent polystyrene. The number average molecular weight of the block copolymer has been reported ${ }^{11}$ to be 76000 and two polystryene blocks of equal length exist primarily at the two ends of the A-B-A molecule. Consequently, the block lengths in molecular weight become approximately $11000-54000-11000$. The polybutadiene consists of $51 \%$ trans $-1,4,41 \%$ cis-1,4, and $8 \%$ vinyl structure. ${ }^{11}$

The film specimens were prepared by casting from dilute solutions. Two different types of solvents were used as casting solvent: One was tetrahydrofuran containing $10 \%$ methyl ethyl ketone by volume (designated as $\mathrm{T} / \mathrm{M}$ ), which is nonpreferential solvent, and the other cyclohexane (designated as $\mathrm{Cy}$ ), which is preferential for polybutadiene.

Arai et al. ${ }^{12}$ observed the electron micro- scope on the films prepared using the same polymer and the same solvents: The sphereshaped polystyrene domains disperses within polybutadiene matrix on $\mathrm{Cy}$-films, and lamella domains of polystyrene and polybutadiene alternately place on $\mathrm{T} / \mathrm{M}$-films.

Polystyrene films were also used in this study. The polystyrene was a commercial polymer, HH-30 (Idemitsu Petrochemical Co., Ltd.). The number average and weight average molecular weights were 107000 and 322000 , respectively.

The dynamic mechanical measurements were carried out using Rheovibron, model DDV-IIB (Toyo Baldwin Co.).

\section{RESULTS AND DISCUSSION}

Dynamic mechanical properties were measured at a frequency of $110 \mathrm{~Hz}$ and at temperatures between $-170^{\circ} \mathrm{C}$ and $110^{\circ} \mathrm{C}$ for both $\mathrm{T} / \mathrm{M}$ - and $\mathrm{Cy}$-films. Two distinct dispersions were observed at $-80^{\circ} \mathrm{C}$ and $100^{\circ} \mathrm{C}$ for both the films. These temperatures are very close to the glass transition temperatures of pure polybutadiene and pure polystyrene, respectively. It is indicated that polybutadiene and polystyrene molecules are well phaseseparated. The dynamic modulus $E^{\prime}$ decreased drastically at the glass transition temperatures for both the films. The decrease in $E^{\prime}$ at $-80^{\circ} \mathrm{C}$ (the glass transition temperature of polybutadiene) was greater for Cy-films (from $10^{9} \mathrm{~Pa}$ to $10^{7} \mathrm{~Pa}$ ) than for $\mathrm{T} / \mathrm{M}$-films (from $10^{9} \mathrm{~Pa}$ to $10^{8} \mathrm{~Pa}$ ). This is consistent with previous morphological observation ${ }^{1-14}$ : Polybutadiene domains support a large part of the stress in the case of Cy-films, while polystyrene as well as polybutadiene domains share the stress in the case of $\mathrm{T} / \mathrm{M}$-films.

As shown in Figures 1 and 2, a novel dispersion was observed as a shoulder around $65^{\circ} \mathrm{C}$ on the $\tan \delta-T$ plot besides glass transitions of polybutadiene $\left(-80^{\circ} \mathrm{C}\right)$ and polystyrene $\left(100^{\circ} \mathrm{C}\right)$. Figure 1 shows the variation of $\tan \delta$ with temperature for $\mathrm{T} / \mathrm{M}$ - 


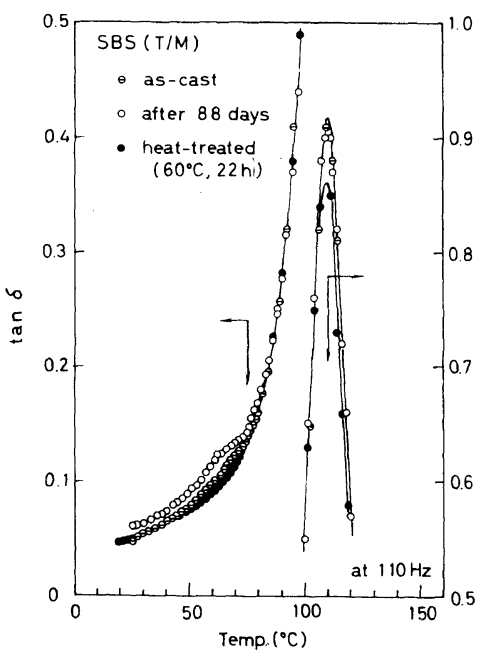

Figure 1. The variation of $\tan \delta$ with temperature for $\mathrm{T} / \mathrm{M}$-films as cast, aged at room temperature for 88 days, and heat-treated at $60^{\circ} \mathrm{C}$ for $22 \mathrm{~h}$.

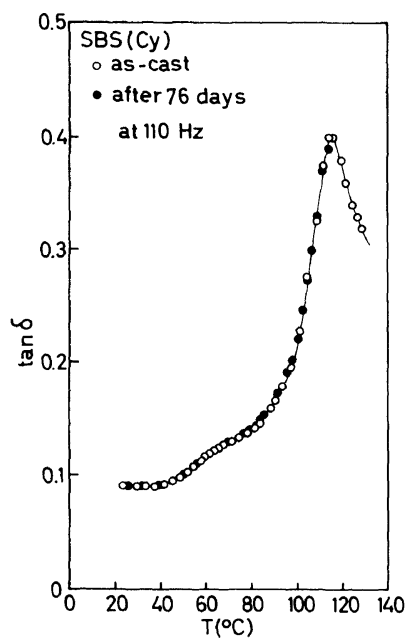

Figure 2. The variation of $\tan \delta$ with temperature for $\mathrm{Cy}$-films as cast and aged at room temperature for 76 days.

films having different thermal histories. As is shown in the figure, the shoulder became bigger by aging at room temperature. The shoulder, on the other hand, disappeared by heat-treating at $60^{\circ} \mathrm{C}$.

For as-cast $\mathrm{Cy}$-films, the similar but more distinct dispersion was observed, as shown in Figure 2. In this case, the dispersion did not
Table I. Density of aged and heat-treated SBS films cast from $\mathrm{T} / \mathrm{M}$ - and $\mathrm{Cy}$-solution

\begin{tabular}{lcc}
\hline & Aged & Heat-treated \\
\hline T/M-Cast films & $0.9415 \pm 0.0003$ & $0.9407 \pm 0.0003$ \\
Cy-Cast films & $0.9419 \pm 0.0003$ & $0.9405 \pm 0.0003$ \\
\hline & & $\left(\mathrm{g} \mathrm{cm}^{-3}\right)$
\end{tabular}

change by aging for 76 days, as shown in the same figure. The dispersion disappeared by heat-treating at $60^{\circ} \mathrm{C}$ for $22 \mathrm{~h}$ in this case, too.

Also at different frequencies $(35,11$, and $3.5 \mathrm{~Hz}$ ), the dynamic mechanical property was measured as a function of temperature. For all kinds of films, the novel dispersion appeared at the same temperature: The dispersion temperature did not change with the frequency. It is suggested that the dispersion cannot be caused by the viscoelastic effect, but by the phase transition such as melting of ordered structure.

The density was measured at $30^{\circ} \mathrm{C}$ using floating method in the mixture of ethyl alcohol and water. The results are summarized in Table I. The density of aged films was significantly higher than that of heat-treated films both for $\mathrm{T} / \mathrm{M}$ - and Cy-films. It is indicated that heat-treating lowers the density.

Figures 3 and 4 show the variation of the velocity and attenuation coefficient of ultrasonic wave with temperature for aged and heat-treated $\mathrm{T} / \mathrm{M}$-films and those for $\mathrm{Cy}$-films, respectively. The resonant frequency of ultrasonic wave was $150 \mathrm{kHz}$. As is obvious from the figures, the velocity decrased with increasing temperature for all the films, while the attenuation coefficient increased. The velocity for Cy-cast films was lower than that for $\mathrm{T} / \mathrm{M}$-films, while the attenuation coefficient was higher. These are quite normal: The latter can be ascribed to the difference in their morphology. Usually, rubbery materials have lower velocity and higher attenuation coefficient than glassy materials. Therefore, in the case of Cy-films in which the continuous phase 


\section{A. TAnaka $e t$ al.}

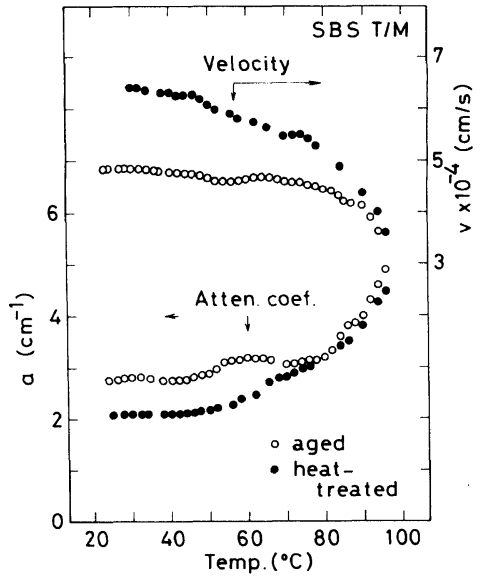

Figure 3. The variations of the velocity and attenuation coefficient with temperature for $\mathrm{T} / \mathrm{M}$-films aged at room temperature and heat-treated at $60^{\circ} \mathrm{C}$.

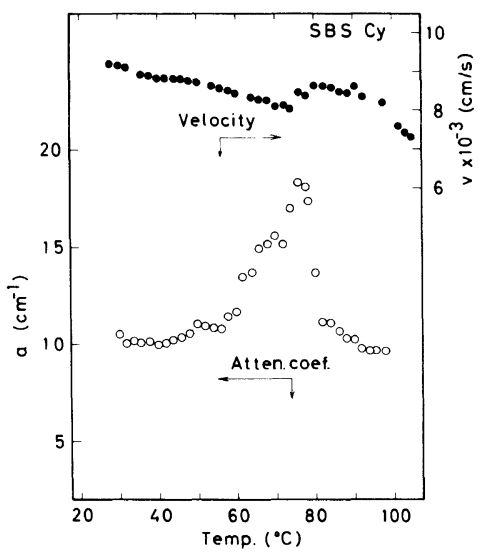

Figure 4. The variations of the velocity and attenuation coefficient with temperature for $\mathrm{Cy}$-films.

is composed of rubbery polybutadiene phase, the velocity is low and the attenuation is high. In the case of $\mathrm{T} / \mathrm{M}$-films in which the ultrasonic wave travels through the both glassy polystyrene and rubbery polybutadiene phases, the velocity is higher and the attenuation is lower than in the case of $\mathrm{Cy}$-films.

The followings are noteworthy. First the velocity for aged $\mathrm{T} / \mathrm{M}$-films was lower than that for heat-treated $\mathrm{T} / \mathrm{M}$-films, and the attenuation coefficient was higher. Above $80^{\circ} \mathrm{C}$, however, both velocity and attenuation coefficient were close together.

The increase in the density raises the velocity and lowers the attenuation coefficient. the fluctuation of the density must also affects both the velocity and the attenuation coeffcient $^{17,18}$ : The density fluctuation lowers the velocity and it raises the attenuation coefficient. Considering this together with density data, one can ascribe the lower velocity and higher attenuation coefficient on the aged $\mathrm{T} / \mathrm{M}$-films to the fluctuation of the density. Here, it should be noticed that the heterogeneous (fluctuated) state has a higher density than homogeneous one. This may lead a conclusion that the heterogeneous state may be caused by local ordering. A different type of heterogeneous state such that residual (thermal or mechanical) stress is frozen will be denied from the density data. Because it is considered that heterogeneous state caused by residual stress might have lower density than homogeneous state.

Second, in the case of aged $\mathrm{T} / \mathrm{M}$-films, a downward peak was observed between $50^{\circ} \mathrm{C}$ and $75^{\circ} \mathrm{C}$ on the plot of the velocity $v s$. temperature, and an upward peak was observed between $50^{\circ} \mathrm{C}$ and $80^{\circ} \mathrm{C}$ on the plot of the attenuation coefficient $v s$. temperature. In the case of heat-treated T/M-films, however, no distinct peak was observed on their plots. In the case of Cy-films, a relatively broad downward peak was observed between $50^{\circ} \mathrm{C}$ and $75^{\circ} \mathrm{C}$ on the plot of the velocity $v s$. temperature, and a big upward peak was observed between $50^{\circ} \mathrm{C}$ and $80^{\circ} \mathrm{C}$ on the plot of the attenuation coefficient vs. temperature.

Ultrasonic peaks frequently appear at phase transition. Hence, the appearance of the ultrasonic peak would also indicate the existence of ordered state. However, we cannot specify the ordered state at the present stage. As one of the possibilities, it is considered that the ordered region is composed of the regular spacing of phenyl groups. This point will be experimentally investigated in the future.

DSC studies supported the existence of 


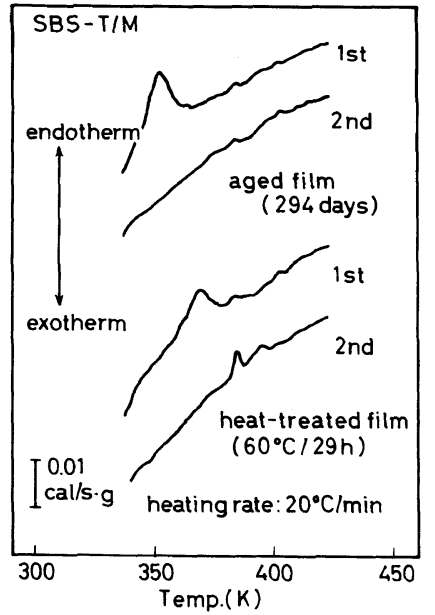

Figure 5. DSC scans for T/M-films aged for 294 days at room temperature and heat-treated at $60^{\circ} \mathrm{C}$ for $29 \mathrm{~h}$. The heating rate was $20^{\circ} \mathrm{C} \mathrm{min}{ }^{-1}$. The second run was carried out after the sample specimen was cooled down to $320 \mathrm{~K} \mathrm{~min}^{-1}$.

molecularly ordered state, as described below. Figure 5 shows the DSC scans of aged (294 days) and heat-treated $\left(60^{\circ} \mathrm{C} / 29 \mathrm{~h}\right) \mathrm{T} / \mathrm{M}$-films. The heating rate was $20 \mathrm{~K} \mathrm{~min}^{-1}$. The second run was carried out after sample specimen was cooled down at the rate of $320 \mathrm{~K} \mathrm{~min}^{-1}$. For aged films, an endothermic peak appeared around $350 \mathrm{~K}$ on the first run. For heat-treated films, however, the peak did not appear around $350 \mathrm{~K}$, but a small peak appeared around $370 \mathrm{~K}$. Both endothermic peaks disappeared on the second run.

Illers, ${ }^{19}$ Kovacs et al. ${ }^{20}$ Tant et al. ${ }^{21}$, and Hodge et al. ${ }^{22-25}$ have observed the endothermic heat capacity peak below $T_{\mathrm{g}}$ (sub- $T_{\mathrm{g}}$ peak) in several polymers. It was presented that the sub- $T_{\mathrm{g}}$ peak increases in the magnitude and shifts to higher temperature with increasing annealing time (or aging time) and annealing temperature. Hodge et al. ${ }^{22-25}$ indicated that the development of sub- $T_{\mathrm{g}}$ peaks with aging is a consequence of the glass transition kinetics.

The peak appearing at $370 \mathrm{~K}$ for heat-treated films might be due to the glass transition kinetics (enthalpy relaxation). The peak caused

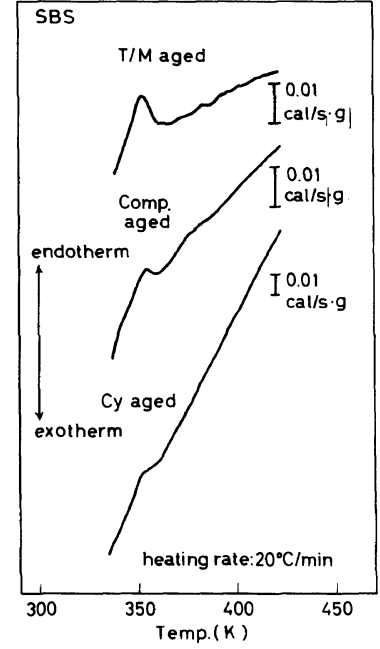

Figure 6. DSC scans for $\mathrm{T} / \mathrm{M}-, \mathrm{Cy}-$, and compression molded SBS films aged at room temperature.

by the glass transition kinetics should shift to higher temperatures than $370 \mathrm{~K}$ with increasing aging time, as described above. Thus, it is unlikely that the peak appearing at $350 \mathrm{~K}$ on aged films is due to the glass transition kinetics. Moreover, this is supported from the following observation: As shown in Figure 6, all the endothermic peaks for three kinds $(\mathrm{T} / \mathrm{M}, \mathrm{Cy}$, and Comp-molded) of aged films appeared at the same temperature $(350 \mathrm{~K})$, in spite of the fact that the aging condition such as aging time differed from sample to sample. Aging time was $c a .300$ days for T/M-films, $c a .60$ days for Cy-films, and ca. 20 days for Comp-molded films. This observation rather indicates that the peak at $350 \mathrm{~K}$ is ascribed to the melting of ordered structure.

The dynamic mechanical test was done also on pure polystyrene films. The films were prepared by melt-pressing, and by casting from the $\mathrm{T} / \mathrm{M}$ - and $\mathrm{Cy}$-solution. One did not observe any novel dispersion on melt-pressed and $\mathrm{T} / \mathrm{M}$-cast films. However, when melt-pressed polystyrene film was elongated by $c a$. $10 \%$ around $T_{\mathrm{g}}\left(100^{\circ} \mathrm{C}\right)$ and then air-cooled, the novel dispersion was observed (see Figure 7). The dispersion disappeared by heat-treating in 


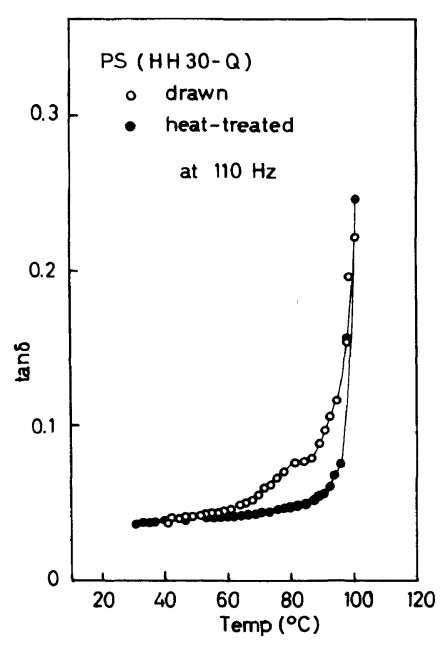

Figure 7. The variation of $\tan \delta$ with temperature for polystyrene films. Open circles denote the films which were elongated by $c a$. $10 \%$ around $95^{\circ} \mathrm{C}$ and then quickly dropped down to room temperature. Close circles the films heat-treated at $60^{\circ} \mathrm{C}$.

this case, too (also see Figure 7). The novel dispersion was also observed on Cy-cast polystyrene films. The novel dispersions were very similar to those observed on SBS films. This suggests that the molecular ordering may occur in the polystyrene domain but neither in polybutadiene domain nor in their interface region.

Some forces are necessary for molecular ordering to be derived and to be stabilized. In the case of T/M-films, the deriving and stabilizing force is supposed to be entropic force of rubbery polybutadiene chains: The entropic force may have an effect to restrain the mobility of polystyrene molecules. In the case of Cy-films, on the other hand, it seems to be exclusion force: when the films are cast from cyclohexane which is a preferential solvent for polybutadiene, polystyrene molecules must be preferentially excluded from cyclohexane molecules. The exclusion force will cause molecular ordering in polystyrene molecules. The molecular ordering thus formed may be stabilized by entropic force of rubbery polybutadiene chains.
In conclusion, the novel dispersion can be ascribed to the transition phenomenon of ordered structure formed in the polystyrene domain. The ordered structure may be derived by some forces in nonequilibrium circumstances. Finally, the authors would like to emphasize the following point: The concept which molecular ordered state is possibly formed under the nonequilibrium circumstance is important in polymer physics as well as in a practical use of polymeric materials.

\section{REFERENCES}

1. G. D. Wignal and G. W. Longman, Polym. Prepr., 15, 18 (1974).

2. P. H. Geil, J. Macromol. Sci.-Phys., B12, 173 (1976).

3. P. J. Harget and J. M. Aharoni, J. Macromol. Sci.-Phys., B12, 209 (1976).

4. W. Knappe and H. J. Otto, J. Macromol Sci.-Phys., B12, 225 (1976).

5. R. F. Boyer, J. Macromol. Sci-Phys., B12, 253 (1976).

6. A. Colebrooke and A. H. Windle, J. Macromol. Sci.-Phys., B12, 373 (1976).

7. K. P. Grosskurtz, Colloid Polym. Sci., 225, 120 (1977).

8. A. V. Sidrovich and Y. S. Nadezhin, J. Macromol. Sci.-Phys., B16, 35 (1979).

9. L. Onsager, Ann. N.Y. Acad. Sci., 51, 627 (1949).

10. W. Maier and A. Saupe, Z. Naturforsch., 13a, 564 (1958).

11. J. F. Beecher, L. Marker, R. D. Bradford, and S. L. Aggarwal, J. Polym. Sci., C, 26, 117 (1969).

12. K. Arai, T. Miki, and T. Kotaka, Polym. Prepr. Jpn., 27, 406 (1978).

13. T. Miyamoto, K. Kodama, and K. Shibayama, $J$. Polym. Sci., A-2, 8, 2095 (1970).

14. G. Kraus, K. W. Rollmann, and J. O. Gradner, $J$. Polym. Sci., Polym. Phys. Ed., 10, 2061 (1972).

15. A. Takana, Y. Jono, and S. Onogi, Rep. Prog. Polym. Phys. Jpn., 24, 295 (1981).

16. A. Tanaka, M. Shinohara, N. Wakabayashi, and S. Onogi, Rep. Prog. Polym. Phys. Jpn., 26, 305 (1981).

17. J. C. Slater and N. H. Frank, "Mechanics," McGraw-Hill, New York, N. Y., 1947.

18. J. B. Marion, "Classical Dynamics of Particles and Systems," Academic Press, New York, N.Y., 1965.

19. K. H. Illers, Makromol. Chem., 127, 1 (1966).

20. A. J. Kovacs, J. J. Aklonis, J. M. Hutchingson, and A. R. Ramos, J. Polym. Sci., Polym. Phys. Ed., 17, 1097 (1979).

21. M. R. Tant and G. L. Wilkes, Polym. Eng. Sci., 21, 325 (1981). 


\section{A Novel Mechanical Dispersion and Molecular Ordering}

22. I. M. Hodge and A. R. Berens, Macromolecules, 14, 24. I. M. Hodge and G. S. Huvard, Macromolecules, 16, 1598 (1981).

371 (1983).

23. I. M. Hodge and A. R. Berens, Macromolecules, 15, 25. I. M. Hodge, Macromolecules, 16, 898 (1983). 762 (1982). 